\title{
A gripe espanhola em Mato Grosso e suas lições em tempos de pandemia da COVID-19
}

\section{The Spanish flu in Mato Grosso and its lessons in times of COVID-19 pandemic}

\author{
Manuela Areias Costa*
}

Universidade Estadual de Mato Grosso do Sul (UEMS), Dourados, MS, Brasil

\footnotetext{
* E-mail: manuelaareiasc@gmail.com
}

\section{RESUMO}

Introdução: Este artigo tem como objetivo analisar os impactos políticos e sociais da gripe espanhola em Mato Grosso e trazer reflexões sobre a pandemia da COVID-19. Para tanto, pretende-se recuperar a memória da gripe espanhola por meio da análise dos registros da imprensa mato-grossense da época. Discussão: A epidemia, conhecida como “Influenza Hespanhola", marcou o início do século XX, e guarda diversas semelhanças com a situação que estamos enfrentando atualmente, frente à pandemia da COVID-19, apesar dos 100 anos que as separam, sobretudo em relação à postura negacionista das autoridades no passado e nos tempos atuais. Conclusões: 0 resgate da memória da gripe espanhola oferece lições e experiências que poderiam ser aproveitadas em níveis local e nacional no combate ao coronavírus.

PALAVRAS-CHAVE: Gripe Espanhola; Jornais; Coronavírus

\begin{abstract}
Introduction: This article analyzes the political and social impacts of the Spanish flu in Mato Grosso and brings reflections on the COVID-19 pandemic. To this end, it intends to recover the memory of the Spanish flu by analyzing the records of the Mato Grosso press at the time. Discussion: The epidemic known as "Influenza Hespanhola", marked the beginning of the twentieth century, and has numerous similarities with the situation we are facing today, in the face of the COVID-19 pandemic, despite the 100 years that separate them, especially in relation to the denial posture of the authorities in the past and in the present times. Conclusions: The rescue of the memory of the Spanish flu offers lessons and experiences that could be used at local and national levels to fight the new coronavirus.
\end{abstract}

KEYWORDS: Spanish Flu; Newspapers; Coronavirus 


\section{INTRODUÇÃO}

“HONTEM era um simples RESFRIADO... HOJE é uma GRIPPE perigosa!"1

A epidemia da "influenza hespanhola"* é considerada uma das mais devastadoras da história. Esta enfermidade se alastrou por diversos países, dizimando entre 20 e 40 milhões de pessoas, entre os anos de 1918 e 1920, de acordo com os dados da Organização Mundial de Saúde (OMS). No tocante ao número de doentes, supõe-se que teriam adoecido cerca de 600 milhões de pessoas ${ }^{2}$. Não há uma contabilização exata do número de vítimas no Brasil, porém estima-se que 35 mil pessoas tenham sido mortas pela influenza espanhola. Esses números não são precisos, em razão das subnotificações dos casos, principalmente entre as populações mais vulneráveis (como indígenas e afro-brasileiros), e os óbitos registrados conforme as complicações provocadas pela gripe.

Na cidade de São Paulo, em poucos meses a epidemia matou cerca de 5 mil paulistanos. Os corpos das vítimas se acumulavam nas ruas até serem recolhidos, ampliando o cenário de devastação. A cidade do Rio de Janeiro viveu uma situação semelhante. No Rio de Janeiro, famílias inteiras foram dizimadas, sobretudo as que viviam em condições mais vulneráveis nas periferias. A doença propagou-se em toda a capital e no interior. Em 27 de outubro de 1918, o jornal A Cruz anunciou que nesta localidade a doença estava

[...] começando a penetrar no interior, o aspecto do Rio é lamentável, todo o comércio está fechado, a Avenida deserta. O movimento de médicos e farmácias extraordinário, não há famílias sem três ou quatro casos, em geral com caráter benigno, porém causando muitos falecimentos $[\ldots]^{3}$.

Estima-se que a epidemia causou a morte de cerca de $15 \mathrm{mil}$ pessoas no Rio. 0 pânico tomou conta da cidade do Rio de Janeiro, então capital da República Federal, à medida que os casos aumentavam em número e gravidade. Em poucos dias, serviços públicos como escolas e repartições foram interrompidos e o atendimento na área da saúde se tornou caótico ${ }^{4}$. A situação instaurada pela epidemia de gripe espanhola foi vinculada à negligência, ao descaso e à incompetência administrativa do governo, fatores amplamente explorados pelos jornais. Tal situação crítica levou à renúncia do então Diretor-geral de Saúde Pública, Carlos Seidl. Como argumentou a historiadora Adriana da Costa Goulart, “o contexto instaurado durante a epidemia acabou fazendo com que o diretor se tornasse uma espécie de bode expiatório do evento, por meio de uma grande campanha difamatória pela qual se torna motivo de chalaça para os jornais e a população"5. Diante da renúncia de Seidl, em outubro de 1918, o pesquisador Carlos Chagas, então diretor do Instituto Oswaldo Cruz, passou a atuar no controle da epidemia. Em 31 de outubro, o jornal o Matto Grosso, anunciava que Seidl deixava seu cargo de diretor da saúde pública, assumindo em seu lugar, o Dr. Carlos Chagas, que emergia, naquele momento, como herói no combate à epidemia.
RIO, 27- "O Dr. Carlos Seidl deixa seu cargo de diretor da saúde pública". O governo deu amplos poderes ao substituto do Dr. Seidl, encarregando ainda o Dr. Carlos Chagas e outros de atender a população. Postos de socorros foram em grande quantidade distribuídos por toda cidade; as escolas públicas foram transformadas em hospitais, muitas farmácias foram requisitadas pelo governo; todos os médicos e farmacêuticos apresentaram-se afim de prestar os seus serviços. Tem vindo para o Rio médicos de outros estados. [...] A cidade está morta, o comércio fechado e bem assim os cinemas, teatros e outras casas de diversões. Não há memória de uma tão terrível calamidade ${ }^{6}$.

A historiadora Gabrielle Alves argumenta que, até aquele momento, considerava-se a gripe espanhola uma doença comum e benigna, que atacava sobretudo idosos. Porém, a epidemia de 1918 acabou alterando a idade da população afetada. Morreram, sobretudo homens adultos, entre 20 e 40 anos (trabalhadores), o que surpreendeu a classe médica, que acreditava que a doença atingiria em maior proporção as pessoas idosas. “As vítimas provavelmente precisavam sair de casa para trabalhar, e acabavam assim sendo infectadas"2.

Após notícias da crise de saúde instaurada pela gripe espanhola no Rio de Janeiro e São Paulo, o inspetor de higiene do estado de Mato Grosso, Dr. Caio Corrêa, enviou, no mês de outubro de 1918, telegramas para o diretor de serviço sanitário do estado de São Paulo, Arthur Neiva, pedindo informações sobre medidas profiláticas adotadas em seu estado no combate à influenza. Neiva respondeu ao telegrama informando que “[...] não há preventivo seguro contra a epidemia de influenza. Indicamos o uso do quinino e evitar as aglomerações, resfriamentos e fadigas. A enfermidade tem pequeno poder de disseminação, mas por enquanto se manifesta com pequena mortalidade [...]"3. As principais recomendações de combate à influenza no país foram: evitar aglomerações, higienizar nariz e garganta e evitar fadiga e excesso de atividades físicas. Medicamentos com soluções de quinino, citado por Neiva, substância com funções antitérmicas e analgésicas, também usada no tratamento da malária e arritmias cardíacas; Emulsão Scott, "fortificante poderoso na convalescença da Grippe Hespanhola" 7, Água Purgativa Queiroz, “O antídoto mais seguro ou a melhor arma de combate ao terrível flagello GRIPPE HESPANHOLA"8, Instatina, "corta os resfriados e allivia as dores" 9 , entre outros remédios - indicados sem respaldo científico - eram propagados como milagrosos no combate à influenza e estampavam os classificados dos jornais de 1918.

Alguns dias após a troca de telegramas entre Arthur Neiva e Caio Corrêa, o jornal A Cruz publicou medidas preventivas de combate à epidemia. As recomendações do Dr. Caio Corrêa, inspetor de higiene do estado, relacionavam-se a cuidados higiênicos, sintomas da doença e seu tratamento, e cuidados com os doentes.

\footnotetext{
* Foi mantida a grafia original dos jornais da época (início do século XX) em citações e partes do texto.
} 
I - CUIDADOS HYGIENICOS: Evitar de todos os modos aglomerações em ambientes pouco arejados, principalmente em dormitórios.

Evitar os resfriados, a fadiga, o excesso de alimentação, as bebidas alcoólicas e os gelados.

Manter as casas e suas dependências sempre arejadas e limpas, extinguindo a criação de porcos, onde não houver local apropriado e não permitido a existência de poças d'água estagnadas.

É também indicado como preservativo a vacina antivariólica; isto é a mesma que serve contra as bexigas, contando que não seja recente.

II - SYMPTOMAS DA MOLÉSTIA: Em geral, a GRIPPE ou INFLUENZA, começa com dores de cabeça e de todo o corpo, calafrios, febre alta, tonturas e abatimento geral. Frequentemente aparece tosse ou rouquidão, catarro no nariz, garganta e bronchios. Em alguns doentes ela se manifesta sob a forma de gastro-intestinal, com vômitos, diarreia, tympanismo abdominal (ventre empachado) e cólicas intestinais.

III - TRATAMENTO: Caso não seja possível recorrer ao médico, o doente deverá tomar um purgativo salino. Por exemplo: Trinta gramas de sulfato de sódio (Sal de Glauber) dissolvidas em um copo d'água, tomar de uma vez. Ou então a água de Rubinat (um copo cheio), Purgol ou Sal Pecê. Contra a febre, usar qualquer das seguintes fórmulas [...].

IV - CUIDADOS COM OS DOENTES: Os doentes devem estar separados das outras pessoas da casa. Convém usarem gargarejos com solução de clorato de potássio ou de ácido bórico ou de água oxigenada. Convém desinfetarem o nariz, várias vezes ao dia, com algumas gotas de óleo gomenolado e mentholado a $4 \%$. Devem evacuar e escarrar em vasos apropriados, contendo solução desinfectante. A alimentação constará, nos primeiros dias, de leite, café, chá preto e água. 0 repouso é necessário mesmo durante a convalescença. Cuiabá, 5 de Novembro de 1918. (Dr. Caio Corrêa- Inspector de Hygiene) $)^{10}$.

O relatório do governo de Dom Aquino Correia, eleito governador de Mato Grosso pelo Partido Republicano Mato-grossense em 1918, analisado pelo pesquisador Suelme Fernandes, apresenta o número de contaminados e mortos pela influenza entre os meses de outubro de 1918 a janeiro de 1919, totalizando, aproximadamente, 27 mil pessoas contaminadas em todo Estado. A epidemia atingiu 19 municípios, levando cerca de 700 pessoas a óbito. Entretanto, essa contabilização não é precisa. É possível que esses números tenham sido bem maiores que o relatado no documento, em razão das subnotificações de dados da transmissão da doença, sobretudo entre as comunidades tradicionais do estado (indígenas, negras rurais e quilombolas, pescadores e ribeirinhos). De acordo com a análise de Fernandes, Cuiabá, Corumbá, Coxim, Campo Grande, Rosário d'Oeste, Nossa Senhora do Livramento, Poconé e Cáceres foram as cidades com os maiores índices de casos de contaminação. Na capital (Cuiabá) ocorreram 3 mil casos de contaminação, levando a óbito 29 pessoas. No município de Corumbá, localizado no Sul do estado, ocorreu o maior número de mortes, chegando a 160 vítimas em três meses ${ }^{11}$.

Os discursos dos jornais locais da época atribuíam a chegada do vírus influenza ao estado, a partir do mês de setembro do ano de $1918^{12}$, por meio de passageiros das embarcações que chegavam pelo porto de Corumbá e seguiam até a capital. Os barcos a vapor passavam pelas cidades de Cuiabá, Cáceres, Corumbá, Assunção, Buenos Aires, Montevidéu, Torres, Santos e Rio de Janeiro $^{13}$. Tal roteiro fluvial tinha em Mato Grosso os rios Paraguai e Cuiabá como os principais caminhos; saindo pelo porto de Cuiabá, alcançava os rios São Lourenço e Paraguai; seguia pelo Paraná e Prata, até cair no oceano Atlântico, almejando chegar no Rio de Janeiro.

Após notícias da chegada da epidemia no Rio de Janeiro, o governo de Mato Grosso passou a fiscalizar, a partir do mês de outubro, a chegada das embarcações procedentes de Corumbá no porto do rio Cuiabá. Na região denominada "Amolar", localizada à margem do rio Paraguai e próxima à Corumbá, foi criado um posto sanitário para inspecionar e desinfetar as embarcações, bem como observar seus passageiros ${ }^{14}$.

Além da criação do posto médico do Amolar, sob o comando do inspetor de higiene, estabeleceu-se comissões para realizar a profilaxia da doença em cinco zonas da cidade de Cuiabá. Essas zonas se distribuíram em: $1^{\circ}$ - centro da cidade, entre a rua Barão de Melgaço e a margem direita do córrego da Prainha; $2^{\circ}$ - da rua Barão de Melgaço, subindo os bairros da Boa Morte e Lavapés; $3^{\circ}$ - da avenida Ponce até o Largo do Arsenal; $4^{\circ}$ - do bairro do $2^{\circ}$ Distrito até o rio Cuiabá; $5^{\circ}$ - bairros do Areão, Bahú, Mundéo e margem esquerda do córrego. As visitas às habitações dos bairros da cidade eram acompanhadas por clínicos, que realizavam a "prophylaxia offensiva", que visava "impedir que o gérmen encontre terreno próprio para medrar"; e, no caso dos enfermos, faziam a "prophylaxia defensiva" - "o tratamento dos doentes e seu possível isolamento sempre que for possível, quer em domicílio, quer em hospital". Os enfermos mais abastados eram tratados pelos médicos em casa, mas a grande maioria dos infectados da cidade de Cuiabá era internada na Santa Casa de Misericórdia ou no Hospital São João dos Lázaros ${ }^{15}$. Se na capital a estrutura de saúde era precária, a situação de calamidade do interior, sobretudo no Sul do estado e nas zonas rurais das cidades, era ainda mais alarmante.

\section{DISCUSSÃO}

A contaminação em terras brasileiras ocorreu quando uma embarcação inglesa, o navio "Demerara", atracou em três cidades do Brasil: Recife, Salvador e Rio de Janeiro, no final do mês de agosto de 1918. A partir daí, começaram a ser registrados os primeiros doentes de gripe espanhola no país. Os jornais brasileiros, antes de o vírus chegar no país, ignoraram ou deram pouco espaço aos relatos sobre a epidemia. Após a chegada da influenza e o aumento substancial do número de infectados, passaram a cobrar das autoridades medidas consistentes na área da saúde pública. 
Os discursos dos jornais de Mato Grosso, assim como os da imprensa de outros estados brasileiros, evidenciam que, em um primeiro momento, as autoridades negaram a epidemia, uma vez que era algo desconhecido e com potencial para gerar impactos na economia e nos sistemas de saúde. Os relatos relacionavam a influenza espanhola a uma gripe passageira, que atingiria apenas idosos. Desse modo, estes deveriam ser isolados para controlar o avanço do vírus, sem gerar maiores impactos. Para Alves, de início não foram tomadas providências enérgicas para combater a epidemia, pois Carlos Seidl insistia que a gripe tinha um caráter benigno (tratava-se apenas de uma "gripezinha"). Seidl pediu a censura dos jornais, pois acreditava que instauravam um crescente pânico de epidemia na sociedade, ameaçando a preservação da ordem pública. Conforme Alves, em muitos estados brasileiros, os jornais foram censurados e proibidos de divulgar determinadas notícias a respeito da epidemia, incluindo o número de infectados e de mortos ${ }^{2}$.

A negação e despreocupação em relação à epidemia também são demonstradas nas páginas do jornal $O$ Matto Grosso, que se referia à notícia da chegada da doença no estado como "simples boatos causados pelas espalhafatosas notícias e comentários da imprensa desta cidade". A gripe espanhola era apresentada como uma doença de caráter benigno, pois não passava de um resfriado comum. A "influenza fobia", mencionada no periódico, poderia prejudicar as atividades econômicas. Segundo o seu redator Floriano Lemes,

Corre o boato de já haver vários casos, nesta cidade, da celebrada influenza hespanhola. A população encontra-se alarmada. Já estou cansado de repetir, de casa em casa, e de escrever, de artigo em artigo, que não há fundamento no boato, nem razão no alarme. Os poucos doentes que se acham retidos no leito, em toda essa capital, são todos presas de doenças comuns: ou influenza banal, ou infecções intestinais.

Recorro a um último argumento, para ver se convenço a população: quando a epidemia se alastrar entre nós (caso Deus não queira livrar dela), será impossível a quem quer que seja escondê-la $[\ldots]$

O que a pode tornar tremenda é o pânico com que as populações mal avisadas the têm recebido a importuna visita, como sucedeu no Rio [...]

Longe de nós querer diminuir a gravidade da condição atual desta cidade, assolada por uma epidemia de influenza verdadeira. Mas há um estado de pânico, uma influenza fobia, que devem ser batidos, por prejudiciais nos doentes, aos sãos, e às atividades necessárias. A desordem dos espíritos gera a desordem das coisas.

Esta influenza que nos ataca, o seu característico epidemiológico é o de uma grande mobilidade, isto é, proporção de doentes, e uma mortalidade relativamente pequena. [...]

Mesmo que a epidemia estale entre nós, estamos de alguma sorte preparados para defrontá-la. Tivemos algum tempo para fazer alguma coisa nesse sentido - o que não aconteceu com outras cidades ou Estados ${ }^{16}$.
Conforme Lemes, não havia motivos para tanto alarde em Cuiabá e demais cidades do estado, pois os poucos doentes da capital foram vítimas de "doenças comuns: ou influenza banal, ou infecções intestinais", criticando assim, o "estado de pânico, uma influenza fobia, que devem ser batidos, por prejudiciais nos doentes, aos sãos, e às atividades necessárias”. Nesta mesma edição, Lemes afirma que "A influenza ou "gripe hespanhola" continua servindo também para explorações políticas e pretexto para cavações de dinheiro. 0 pânico pela quarentena como está sendo dirigida pelo Dr. Amarante envergonha qualquer civilizado [...]"17. Amarante era o médico responsável por inspecionar as embarcações e observar os passageiros que chegavam no Amolar. Caso encontrasse vestígios de contaminação durante as suas vistorias, encaminhava os passageiros para uma quarentena obrigatória.

Em 31 de outubro de 1918, o Matto Grosso publicou uma nota informando que "o estado sanitário de Corumbá é excelente. Não tem fundamento os boatos alarmantes propalados pela imprensa". O jornal afirmou que a existência da influenza espanhola em Corumbá era apenas um boato espalhado pela imprensa local, que alarmava o povo com notícias "demasiadamente exageradas" pois, até o momento, a cidade não havia registrado "um só caso".

CORUMBÁ, 29, - Sabe-se aqui que ahi o povo acredita na existência nesta cidade da "Influenza Hespanhola" o que não passa de simples boatos causados pelas espalhafatosas notícias e comentários da imprensa desta cidade, que há muitos dias vem alarmando o povo com notícias demasiadamente exageradas, o ponto de noticiar a existência dessa terrível epidemia aqui, quando ainda até agora não só registrou um só caso [... $]^{18}$.

Um mês depois, esse jornal continuou afirmando que a doença não passava de uma influenza comum e corriqueira, mesmo com o aumento do número de óbitos em Corumbá. No final do mês de novembro, noticiou que o município de Corumbá havia registrado 24 óbitos, porém, apenas seis decorrentes da gripe epidêmica. É possível que o número de infectados e mortos por influenza espanhola tenha sido omitido, pois, como mencionamos anteriormente, esses dados poderiam gerar um crescente pânico de epidemia, ameaçando a economia local e a preservação da ordem pública.

CORUMBÁ, 30 - Registraram-se durante o mês que hoje finda 24 óbitos, dos quais seis apenas de gripe epidêmica. Destes seis casos, três faleceram no hospital de caridade. Continuo a afirmar que a enfermidade não tem aqui o caráter que the emprestam os interesses subalternos, sendo os seus sintomas apenas mais acentuados e mais intensos que os da influenza comum $[\ldots]^{19}$.

De forma semelhante às notícias propagadas sobre a capital e Corumbá, no tocante ao grau de negação da epidemia, os casos de contaminação por influenza espanhola em outros municípios do Sul do estado - Aquidauana, Campo Grande e Três Lagoas - eram caracterizados pela imprensa como benignos, "fazendo acreditar que se trata de casos isolados de gripe comum, sem o desenvolvimento epidêmico". Em 7 de novembro, O Matto Grosso noticiou: 
"A última hora chegou ao nosso conhecimento ter de facto aparecido a influenza espanhola no Sul do Estado, em Três Lagoas, Campo Grande tendo já atingido Aquidauana, sendo os casos no geral de caráter benigno" ${ }^{20}$. $\mathrm{E}$, uma semana depois, informou que

A não ser em Campo Grande, onde segundo os telegramas que publicamos na seção competente, continuam a se verificar novos casos da gripe hespanhola, felizmente sem caráter grave, as notícias recebidas de Aquidauana e Corumbá são tranquilizadoras, por não ter tido a influenza nessas cidades a difusão característica, fazendo acreditar que se trata de casos isolados de gripe comum, sem o desenvolvimento epidêmico ${ }^{21}$.

Em relação aos povos indígenas de Mato Grosso, não existem dados oficiais que apontem com precisão o número de indígenas que perderam a vida em razão da epidemia. Nota-se uma invisibilidade sobre o alastramento da doença em seus territórios, pois essa questão foi negligenciada pelas autoridades públicas e os meios de comunicação da época. Porém, os povos indígenas foram atuantes na luta por políticas públicas, como demonstraram os kadiwéu, do Sul do estado. Em 7 de novembro de 1918, O Matto Grosso publicou uma nota, na qual evidenciava as reivindicações desse grupo "contra o abandono em que estão por parte do Governo".

Os índios cadyuéos reclamam contra o governo e o serviço de proteção aos índios. [...] Da estação de Guaycurús um grupo de índios cadyuéus vindos da aldeia Alliki, passaram o seguinte telegrama ao Coronel José Alves Ribeiro [...] reclamaram contra o abandono em que estão por parte do Governo. A população ficou dolorosamente impressionada com o estado em que se encontram os ditos índios $[\ldots]^{22}$.

Se até dezembro de 1918 a imprensa do Estado ignorava ou dava pouca vazão aos relatos sobre a epidemia, insistindo que a gripe tinha um caráter benigno, em fevereiro de 1919, O Matto Grosso noticiou o aumento substancial do número de infectados no município de Rosário do Oeste, localizado cerca de $100 \mathrm{~km}$ da capital, cobrando das autoridades providências e medidas consistentes na área da saúde. "A gripe hespanhola [grasas] aqui com intensidade, havendo cada dia numerosos casos novos [...] necessitamos de urgentes providências. A população está sujeita a grandes privações" ${ }^{23}$.

Cabe ressaltar que $O$ Matto Grosso, assim como outros jornais, apresentava propostas políticas bem definidas e explicitava o seu papel de formador de opinião pública, ligado a interesses variados do partido republicano mato-grossense, ao exaltar as ações do governador Dom Aquino Corrêa, o qual havia, segundo seu redator, tomado "eficazes providências" no combate à epidemia. Desse modo, a gripe espanhola possibilita também uma reflexão sobre o jogo político e de poderes relacionado ao sistema institucional republicano no Estado, que criou um repertório que viabilizava a solução de problemas regionais, como foi o caso do próprio combate à epidemia. Conforme argumentou Goulart, as doenças epidêmicas no decorrer da história, incluindo a gripe espanhola, foram influenciadas por fatores políticos e sociais ${ }^{5}$.
O periódico investiu no culto à personalidade de Dom Aquino Corrêa e na construção da sua identidade de herói na luta pela saúde do povo mato-grossense, como demonstra o trecho abaixo:

[...] continua a merecer os mais francos elogios da população o desvelo que para com os seus governados tem tido o honrado chefe do Estado, D. Aquino Correa, tudo fiscalizado e providenciando pessoalmente, fato este que tem determinado essa serenidade de animo que se vem notando em toda população.

O zeloso governador da cidade, por sua vez, tem secundado os patrióticos esforços do governo do Estado, aconselhando a adoção de medidas úteis e proveitosas e tomando outras eficazes providências $[\ldots]^{24}$.

Apesar do aumento do número de casos em diversos municípios mato-grossenses, como Corumbá, Rosário do Oeste e na própria capital, entre o final do ano de 1918 e início de 1919, os jornais começavam a propagar a ideia de que a epidemia havia sido extinta no Estado ou afirmavam, com entusiasmo, que a horrível influenza estava em declínio.

Os últimos despachos telegráficos, recebido por S. Exc. Rvmo, Presidente do Estado e publicados na "Gazeta Oficial" de 18 do corrente, trazem a consoladora notícia de se achar a influenza hespanhola em fraco declineo na cidade de Corumbá e completamente extinta no florescente município de Campo Grande. Graças as enérgicas providencias tomadas pelas dignas autoridades, a terrível gripe não tem conseguido produzir os mesmos horrores de que foram testemunhas vários estados do país [... $]^{25}$.

Igualmente, afirmavam que a epidemia já estava quase desaparecendo do Rio de Janeiro, sendo que outubro, novembro e dezembro foram os piores meses da infecção, os que mais mataram pessoas, tanto na capital federal como em outras cidades brasileiras. Os registros oficiais apresentam o número de 12.386 óbitos pela gripe nos últimos três meses de 1918, na cidade do Rio de Janeiro ${ }^{26}$. Entretanto, O Matto Grosso noticiou que "A influenza hespanhola quase que desapareceu do Rio, atacando muito no interior; os postos de socorro, hospitais provisórios começam a fechar. O posto de saúde Cruz Vermelha Syrio-Brasileira fechará essa semana [...]”27.

Em Cuiabá, no derradeiro dia do mês de janeiro de 1919, o redator d'O Matto Grosso anunciou entusiasticamente o fim da epidemia: "com grande e justificado jubilo que anunciamos ao público a terminação da epidemia, felicitando ao Governo pela eficácia das previdentes medidas empregadas". No trecho abaixo, relaciona o fim da epidemia na capital às medidas sanitárias adotadas pelo estado, como a quarentena estabelecida no posto médico de Amolar, criado para inspecionar e desinfetar as embarcações que faziam a viagem Corumbá-Cuiabá e observar seus passageiros.

[...] A quarentena estabelecida com a criação do Posto Médico de Amolar, trouxe duas vantagens positivas: uma, o retardamento da invasão da cidade pelo morbus, que nos havia de vir por via fluvial; segundo o enfraquecimento 
da virulência do germen, cuja a incubação é pequena, de alguns dias somente, de sorte que, quanto mais dias se aumentavam na viagem de Corumbá a Cuiabá, tantos menos micróbios deviam chegar vivos e possantes a este porto [...] Com efeito, ao contrário do que ocorreu em Corumbá e outras cidades do Sul, o movimento urbano nada sofrera: as repartições públicas funcionavam com regularidades [...] É que os vermes da infecção haviam sem dúvida, aportado à nossa capital enfraquecida na sua virulência, pela maior demora na viagem, e pela desinfecção rigorosa que as embarcações sofriam no Posto do Amolar. De 15 a 30 de dezembro chegaram apenas outras lanhas de Corumbá e trouxeram novo contingente de vírus, a reforçar a quota do que havia. Então, estalaram muitos outros casos, de sorte que o ano findou, entre nós, oferecendo a epidemia o seu maior paroxismo. Podem calcular-se em 2 a 3 mil casos, os que se contaram até 31 de dezembro. [...] Na primeira quinzena de janeiro estabeleceu-se o período de estado da epidemia, mantendo-se ela com uma média de um óbito por dia. [...] É pois, com grande e justificado jubilo que anunciamos ao público a terminação da epidemia, felicitando ao Governo pela eficácia das previdentes medidas empregadas $[\ldots]^{28}$.

Três anos após a chegada da influenza espanhola no país, o Correio do Estado publicou uma nota sobre as consequências devastadoras da epidemia, que irradiou no município de Cuiabá "em proporções alarmantes". O estado encontrava-se em crise, semeando "o luto por quase todo o seu vasto território". "As pessoas desprovidas de recursos e já exaustas, pela carência da vida, atingida pelo morbus, não puderam oferecer resistência - succumbiram fatalmente". Nos cemitérios públicos, "podeis verificar a proporção da mortalidade havida antes e depois do apparecimento da Grippe" ${ }^{12}$.

0 relatório de assistência pública e privada, publicado no ano de 1922, reconheceu que, durante o período da epidemia, o Brasil dispunha do mais "rudimentar aparelho de assistência", sendo "urgentíssima necessidade da organização da nossa Assistência Pública". A gripe espanhola acarretou a valorização do sistema público de saúde. Para Goulart, "o discurso formulado no decorrer da epidemia cumpria a função política de legitimação das demandas por novas decisões, no que se referia à reformulação das instituições e políticas públicas de saúde"5. Segundo o relatório de 1922, "O que porém ficou patente, o que profundamente abalou a moral do nosso povo e, com razão, foi o excessivo número dos quais sucumbiram pela miséria, pela fome e pela falta de socorro médico e farmacêutico". Na capital do país, as pessoas "aglomeradas nos subúrbios, morros e outras zonas esquecidas [...] tiveram a dolorosa oportunidade de sentir todo o horror de cenas verdadeiramente dantescas, macabras, pela hediondez de descrição impossível” 26.

Como argumentou Goulart, "historicamente, epidemias e ideologias se difundem da mesma forma, proporcionando o aparecimento de conflitos sociais e de resistência ao intervencionismo e às tentativas de medicalização da sociedade" ${ }^{5}$. A negligência por parte do poder executivo, a postura "caótica e negacionista" 29 o endosso, sem respaldo científico, a medicamentos que supostamente podem ser eficientes estão presentes tanto nas experiências do passado (no contexto da gripe espanhola) como nos discursos das autoridades sobre a pandemia do novo coronavírus. Os discursos dos governos sobre o controle dessas pandemias conflitam com o número expressivo de infectados e mortos e, consequentemente, com a dificuldade dos profissionais da saúde em atender as pessoas doentes. Em um primeiro momento, os negacionistas de ontem e de hoje consideram que tais epidemias geraram uma "histeria" coletiva, afirmando que a doença não se diferencia de qualquer outra "gripezinha". A ideia de que o vírus não é perigoso justifica que medidas de prevenção, como o isolamento social, são desnecessárias. No início do mês de abril de 2020, o presidente Jair Bolsonaro (sem partido) comunicou, em uma videoconferência com líderes religiosos, que "o novo coronavírus parece estar indo embora do país" ${ }^{30}$, contrariando médicos, levantamentos e projeções do Ministério da Saúde e recomendações da OMS.

A gravidade da COVID-19 demonstra a necessidade de as instituições de promoção da justiça e cidadania pressionarem e cobrarem do poder público ações efetivas de combate à pandemia - que visem a contenção do vírus, cuidados com pessoas infectadas, prevenção, promoção e atenção à saúde e assistência social - e apurações dos casos de negligências, irregularidades e subnotificações por parte das autoridades e meios de comunicação. A situação no Brasil e em diversas cidades dos estados de Mato Grosso e Mato Grosso do Sul é alarmante, evidenciando riscos de uma tragédia social.

O boletim informativo sobre a situação epidemiológica em Mato Grosso, publicado pela Secretaria de Estado e Saúde, em 25 de junho de 2020, aponta como 12.601 o número de casos confirmados de COVID-19, 3.132 só no município de Cuiabá, totalizando 476 óbitos no estado ${ }^{31}$. Em Mato Grosso do Sul, os números vêm aumentando expressivamente, chegando a 6.523 casos confirmados até 25 de junho deste ano, com 61 óbitos. Quanto ao perfil das vítimas, o vírus tem atingido em maiores proporções pessoas do sexo masculino, com idade entre 20 a 49 anos. De acordo com o boletim publicado pela Secretaria de Estado de Saúde, os casos confirmados em Dourados representam 34,45\% e, em Campo Grande, $23,82 \%^{32}$. Neste momento de crescimento intenso do número de casos, muitos municípios, em razão das políticas de flexibilização e afrouxamento do isolamento social adotados, caminham para o descontrole e colapso do sistema hospitalar. As cidades são focos de proliferação da COVID-19, ameaçando também povos e comunidades tradicionais que vivem em áreas urbanas e rurais da região Centro-Oeste.

Nota-se uma ausência de políticas públicas e invisibilidade sobre o alastramento da doença em territórios tradicionais. A pandemia de coronavírus escancara a desigualdade social no país e, por meio desta, encontra as condições ideais para atingir as populações historicamente menos favorecidas. A noção de "necropolítica" no contexto dessa pandemia oferece reflexões sobre as políticas na produção da vida e da morte, evidenciando os mecanismos que o Estado utiliza para decidir quem vive e morre ${ }^{33}$. As fragilidades socioeconômicas, a não efetivação de direitos e políticas públicas, em razão da falência do governo 
atual e de sucessivos governos, e as dinâmicas do racismo estrutural, que atravessa também o atendimento de saúde no país, deixam indígenas e quilombolas em uma situação de vulnerabilidade ainda mais intensa frente à pandemia. Entretanto, se o poder público agir a contento e com estratégias para preservar vidas, considerando os protocolos da OMS e observando as experiências nefastas dos tempos da gripe espanhola, talvez, milhares de vidas possam ser salvas.

\section{CONCLUSÕES}

De acordo com Jean Delumeau, "abordar a história do medo em nossa civilização é apreender o nosso passado mais profundo. Ao mesmo tempo, isso nos arma de lucidez para olhar o futuro" ${ }^{34}$. Para Delumeau, de todos os males, as epidemias certamente eram um dos principais fatores que produziam medo e que ameaçavam as comunidades humanas. 0 medo prevalece em tempos de epidemias, em razão das diversas rupturas que provocam na vida cotidiana e nas relações sociais. Neste sentido, a influenza espanhola oferece lições e experiências que poderiam ser aproveitadas em níveis local e nacional no combate ao coronavírus. Apesar dos 100 anos que as separam, novamente presenciamos uma onda de medo e pânico entre as populações, e os antigos problemas de desigualdades sociais e de saúde pública tornaram-se mais evidentes.

\section{REFERÊNCIAS}

1. HONTEM era um simples RESFRIADO... HOJE é uma GRIPPE perigosa!, A Penna Evangélica, Cuiabá, 14 maio 1938. (BND-Biblioteca Nacional Digital, Hemeroteca).

2. Alves GW. Uma comparação entre a pandemia de gripe espanhola e a pandemia de coronavírus. IFCH-UFRGS Notícias. 13 abr 2020[acesso 30 maio 2020]. Disponível em: https://www.ufrgs.br/coronavirus/ base/uma-comparacao-entre-a-pandemia-de-gripe espanhola-e-a-pandemia-de-coronavirus/

3. Serviço especial. A Cruz, Cuiabá, 27 out 1918. (BND, Hemeroteca).

4. Cabral M, Schatzmayr H. A virologia no estado do Rio de Janeiro: uma visão global. Rio de Janeiro: Fundação Oswaldo Cruz; 2012.

5. Goulart AC. Revisitando a espanhola: a gripe pandêmica de 1918 no Rio de Janeiro. Hist Cienc Saude Manguinhos. 2005;12(1):101-42. https://doi.org/10.1590/S0104-59702005000100006

6. O Dr. Carlos Seidl demite-se de seu cargo. O Matto Grosso, Cuiabá, 31 out 1918. (BND, Hemeroteca).

7. Emulsão de Scott. O Matto Grosso, Cuiabá, 5 dez 1918. (BND, Hemeroteca).

8. Água Purgativa Queiroz. A Gazeta, São Paulo, 29 out 1918. (BND, Hemeroteca).

9. Instatina. A Penna Evangélica, Cuiabá, 21 maio 1938. (BND, Hemeroteca).

10. A influenza hespanhola. A Cruz, Cuiabá, 10 nov 1918. (BND, Hemeroteca).

11. Fernandes S. A pandemia de gripe espanhola em Mato Grosso 1918. HNT Hipernotícias. 25 abr 2020[acesso 27 maio 2020]. Disponível em: https://www.hnt.com.br/artigos/apandemia-de-gripe-espanhola-em-mato-grosso-1918/167366

12. Saude publica e hygiene. Correio do Estado, Cuiabá, $5 \mathrm{dez}$ 1921. (BND, Hemeroteca).

13. Oliveira VWN. Entre o Prata e o Mato Grosso: uma viagem pelo mundo do trabalho marítimo de 1910 a 1930 (Buenos Aires, Montevidéu, Assunção e Corumbá) [tese]. Campinas: Universidade de Campinas; 2002.

14. Posto sanitario do Amolar. Matto Grosso, Cuiabá, 31 out 1918. (BND, Hemeroteca).

15. A Influenza hespanhola e as providencias officiaes, O Matto Grosso, Cuiabá, 31 out 1918. (BND, Hemeroteca).

16. Ainda a Influenza. O Matto Grosso, Cuiabá, 5 dez 1918. (BND, Hemeroteca).

17. Corumbá - A "hespanhola”. O Matto Grosso, Cuiabá, 5 dez 1918. (BND, Hemeroteca).

18. Corumbá. O Matto Grosso, Cuiabá, 31 out 1918. (BND, Hemeroteca).

19. Corumbá. O Matto Grosso, Cuiabá, 5 dez 1918. (BND, Hemeroteca).

20. Influenza hespanhola. O Matto Grosso, Cuiabá, 7 nov 1918. (BND, Hemeroteca).

21. Influenza hespanhola. O Matto Grosso, Cuiabá,14 nov 1918. (BND, Hemeroteca).

22. Aquidauana. O Matto Grosso, Cuiabá, 7 nov 1918 (BND, Hemeroteca).

23. Rozario Oéste. O Matto Grosso, Cuiabá, 16 fev 1919. (BND, Hemeroteca).

24. A Influenza hespanhola. O Matto Grosso, Cuiabá, $5 \mathrm{dez}$ 1918. (BND, Hemeroteca).

25. A Influenza hespanhola. A Cruz, Cuiabá, 15 dez 1918. (BND, Hemeroteca).

26. Mocorvo Filho, A. A assistência pública e a assistência privada (relações e regulamentação). Rio de Janeiro: Departamento da Criança no Brasil; 1922. (BND, Hemeroteca).

27. Notícias do Rio. O Matto Grosso, Cuiabá, 14 nov 1918. (BND, Hemeroteca).

28. A terminação da epidemia e as providencias officiaes. 0 Matto Grosso, Cuiabá, 30 jan 1919. (BND, Hemeroteca).

29. Guimarães L. Combinação de pandemia e governos autoritários no mundo é preocupante, diz Lilia Schwarcz. BBC News. 19 maio 2020[acessado 5 jun 2020]. Disponível em: https: //www.bbc.com/ portuguese/brasil-52682049 
30. Fernandes T. Em live com religiosos, Bolsonaro vai na contramão de especialistas e diz que vírus está indo embora. Folha de S. Paulo. 12 abr 2020[acesso 5 jun 2020]. Disponível em: https://www1.folha.uol.com.br/poder/2020/04/ em-live-com-religiosos-bolsonaro-vai-na-contramao-deespecialistas-e-diz-que-virus-esta-indo-embora.shtml

31. Secretaria de Estado de Saúde do Mato Grosso SES-MT. Situação epidemiológica SRAG e COVID-19. Boletim Informativo $\mathrm{N}^{\circ}$ 109. 25 jun 2020[acesso 25 jun 2020]. Disponível em: http: / /www.noticias. mt.gov.br/documents/14042969/14043087/
BOLETIM+INFORMATIVO+109/7a65f980-e1b1-dcfc-95fo$3 \mathrm{c} 0 \mathrm{cf} 84717 \mathrm{c5}$

32. Governo do Estado de Mato Grosso do Sul. Casos COVID-19 Mato Grosso do Sul, 2020. Boletim de Estado de Saúde. 25 jun 2020[acesso 25 jun 2020]. Disponível em: https: / / www. vs.saude.ms.gov.br/wp-content/uploads/2020/06/BoletimEpidemiol\%C3\%B3gico-COVID-19-2020.06.25.pdf

33. Mbembe A. Necropolítica: biopoder, soberania, estado de exceção, política da morte. São Paulo: N 1; 2018.

34. Delumeau J. História do medo no ocidente. São Paulo: Companhia das Letras; 2001.

Contrubuições da Autora

Costa MA - Concepção, planejamento (desenho do estudo), aquisição, análise, interpretação dos dados e redação do trabalho. A autora aprovou a versão final do trabalho.

Conflito de Interesse

Os autores informam não haver qualquer potencial conflito de interesse com pares e instituições, políticos ou financeiros deste estudo.

Esta publicação está sob a licença Creative Commons Atribuição 3.0 não Adaptada.

Para ver uma cópia desta licença, visite http://creativecommons.org/licenses/by/3.0/deed.pt_BR. 